\title{
Anterior chamber depth measured by two methods in myopic and hyperopic phakic IOL implant
}

\author{
Michele Vetrugno, Nicola Cardascia, Luigi Cardia
}

\begin{abstract}
Aim-To evaluate the accuracy and reliability of the optical versus ultrasonic measurement of anterior chamber depth (ACD) in a group of patients affected by high myopia or hyperopia, before phakic IOL implant.
\end{abstract}

Methods-18 consecutive patients (34 eyes) were enrolled in this study, and asked to undergo phakic IOL implant to correct high myopia or hyperopia. The mean age was 29.5 (SD 3.4) years, the male/female ratio was $10 / 8.13$ patients $(24$ eyes) were myopic (mean myopia $\mathbf{- 1 6 . 1 7}$ (4.39) $\mathrm{D}$, range -9 to $-24 \mathrm{D})$, whereas five patients (10 eyes) were hyperopic (mean hyperopia $7.4(2.01) \mathrm{D}$, range 5.5-11 D). For each patient, ACD was evaluated comparing an optical system (Orbscan topograph system) with a standard A-scan ultrasound system. To evaluate the reliability of the two methods, the average of three optical and 10 ultrasonic consecutive measurements were considered. Statistical analysis was performed by means linear regression.

Results-The average difference between optical and ultrasound values was $0.17(0.1)$ $\mathrm{mm}(4.68 \%(2.52 \%))$. There was a constant underestimation of the ACD with the optical system compared with the ultrasound measurement, more evident in the hyperopic eyes $(5.20 \%(1.95 \%))$ than in myopic ones $(4.46 \%(2.72 \%))$. The reliability of measurements, as showed by the standard deviation values, was higher in the optical system $(0.03(0.02))$ than in the ultrasound $(0.1(0.05))$, with a statistical difference $(p<0.001)$. The linear regression analysis between optical and ultrasound measurements was $0.8992(\mathrm{p}<0.0001)$.

Conclusions-The optical measurement of ACD is an accurate and reliable technique in high myopic and hyperopic eyes. It gives a small underestimation of the ACD values, but it could be preferable to the ultrasound technique, because it demonstrates more repeatability and has the advantages of a non-contact technique.

(Br F Ophthalmol 2000;84:1113-1116)

Anterior chamber depth (ACD) measurement gives important details in cataract surgery (biometric formulas) or in glaucoma (epidemiological studies, laser or surgical procedures). ${ }^{1-9}$
This quantitative measurement is also strictly required to perform refractive surgery, such as excimer laser photorefractive keratectomy or phakic anterior chamber lens (PACL) implant.

In the first case anterior chamber depth is important to set a correct optical zone ablation diameter: larger ablation areas are required in deep anterior chamber. ${ }^{10}$ In the second case, a correct depth measurement can prevent endothelial impairment and represent an important factor to calculate the power of the implanting lens. ${ }^{11-16}$

ACD measurement is usually performed by means of ultrasound biometry that, according to technical procedures, is classified as contact or non-contact (immersion, through the lid). ${ }^{17}$ Ultrasound measurements can be affected by various factors, such as the experience of the operator, the user technique, the differences in probe handling, and the physical conditions in which the measurements are taken. This could be important especially in high myopic eyes, in which the prolonged axial length and the elongation of the vitreous chamber could influence the accuracy of the measurements. Moreover, sometimes a repeated contact of the probe may induce corneal abrasions or infections.

Recently, Orbtek (Salt Lake City, UT, USA) has developed an optical technology to measure anterior chamber depth by means of the Orbscan topographer, based on the same optical scan procedure used to perform corneal pachymetry. Previous works demonstrated the specificity and the sensibility of the Orbscan topographer related to echobiometry as well in the measurement of corneal pachymetry ${ }^{18}{ }^{19}$ as of the anterior chamber depth. ${ }^{20}$

The purpose of this study was to evaluate the specificity and the sensibility of ACD optical biometry in high myopic and high hyperopic patients undergoing phakic anterior chamber lens implant.

\section{Materials and methods}

In this prospective study we enrolled 18 consecutive patients (34 eyes), 10 males, eight females, mean age 29.5 years (range $25-37, \mathrm{SD}$ 3.4) undergoing PACL for high myopia or high hyperopia. Thirteen of them (24 eyes) were affected by high myopia (range -9 to $-24 \mathrm{D}$, mean $-16.17 \mathrm{D}, \mathrm{SD} 4.39 \mathrm{D}, 95 \%$ confidence limit $-18.02 \mathrm{D}$ to $-14.31 \mathrm{D})$, the remaining (five patients, 10 eyes) showed high hyperopia (range 5.5 to $11 \mathrm{D}$, mean $7.4 \mathrm{D}$, SD $2.01 \mathrm{D}$, $95 \%$ confidence limit $5.96 \mathrm{D}$ to $8.84 \mathrm{D}$ ).

Myopic eyes received PACL type Nuvita MA20 (Chiron Vision Co, Irvine, CA, USA), hyperopic ones the Phakic 6 (OII, Claremont, 
CA, USA). In both cases the intraocular lens power was calculated according to the following variables: mean corneal power (mean $\mathrm{K}$ ), refraction and ACD, while the IOL length was calculated by the horizontal white to white +1 mm measurement.

In order to avoid corneal surface irregularities that could affect the regularity of the topographic findings, ACD measurements were performed in all eyes at first by means of the Orbscan topographer (which calculated also the mean corneal power), then by the i-scan echobiometer (OTI, Clermond-Ferrand, France).

The Orbscan topography system, as mentioned above, ${ }^{20}$ consists of a three dimensional scanning slit beam system for analysing corneal surfaces as well as structures of the anterior segment (iris, lens). Surface data points are measured in the $\mathrm{x}, \mathrm{y}$, and $\mathrm{z}$ axes, creating colour coded topographic maps.

The i-scan biometric system, used for ultrasound measurements, is a conventional A-scan ultrasound machine, with a $10 \mathrm{MHz}$ ultrasound probe. Patients were asked to look at the blinking light in the centre of the ultrasound probe. Then the probe was placed in contact with the anaesthetised cornea, and 10 programmed consecutive measurements of axial length were achieved. The anterior chamber depth was automatically calculated by the instrument from the first ultrasound peak to the aqueous/anterior lens interface peak.

To assess the reliability of the two methods, the Orbscan measurements were performed three consecutive times in the same examination by the same physician (NC) and once (10 measurements) with ultrasonic echobiometry by another physician (MV).

Statistical analysis was performed by linear regression analysis on mean values, and one way ANOVA test on differences between optical and ultrasound measurements in myopic and hyperopic eyes. The same ANOVA test was performed to evaluate the differences on standard deviation between myopic and hyperopic measurements. The software used for statistical evaluation included Microsoft Excel 97 SR2 (Microsoft Corporation, Richmond, VA, USA) and Winks Kwikstat (TexaSoft, Cedar Hill, TX, USA, software version 4.6).

\section{Results}

The mean ACD value in the whole sample, by means of the Orbscan system was $3.51(0.25)$ $\mathrm{mm}(95 \%$ CL $3.42 \mathrm{~mm}$ to $3.6 \mathrm{~mm})$; by means of ultrasound $3.67(0.27) \mathrm{mm}$ (95\% CL 3.58 $\mathrm{mm}$ to $3.77 \mathrm{~mm})$. The mean difference between measurements was $0.17(0.10) \mathrm{mm}$ (95\% CL $0.14 \mathrm{~mm}$ to $0.21 \mathrm{~mm})(4.68 \%$ $(2.52 \%), 95 \%$ CL $3.80 \%$ to $5.56 \%)$. As Figure 1 shows, linear regression analysis between optical and ultrasound measurements was $0.8992(\mathrm{p}<0.0001)$.

The difference between ultrasonic and optical measurement in the myopic group was 0.15 (0.12) $\mathrm{mm}$ (95\% CL $0.12 \mathrm{~mm}$ to $0.22 \mathrm{~mm}$ ), $4.46 \%(2.72 \%)(95 \%$ CL $3.31 \%$ to $5.61 \%)$, while in the hyperopic group the mean difference was $0.18(0.08) \mathrm{mm}$ (95\% CL 0.13

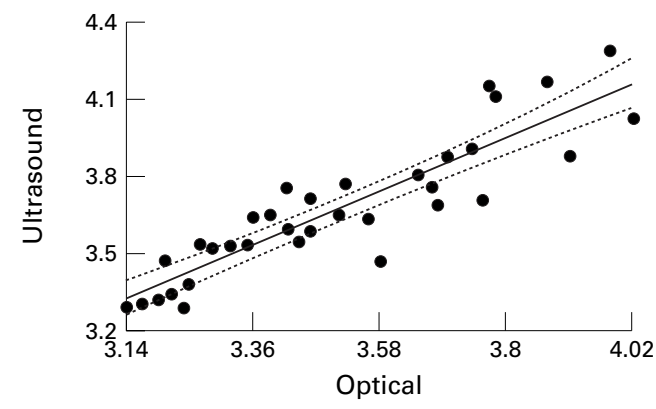

AC depth $(\mathrm{mm})$ in whole sample

Figure 1 Linear regression in the whole sample.

$\mathrm{mm}$ to $0.24 \mathrm{~mm}), 5.20 \%$ (1.95\%) (95\% CL $3.81 \%$ to $6.6 \%$ ). According to spherical equivalent, the correlation slope was significant both in myopic eyes $(r=0.854$, df $22, \mathrm{p}<0.0001)$ and in hyperopic ones $(r=0.9646$, df $8, p<0.0001)$, as shown respectively in Figures 2 and 3.

Performing the one way ANOVA test on differences between optical and ultrasound measurements in myopic and hyperopic groups, we found no statistical differences $(p=0.3415$, df 32).

Figure 4 shows the reliability of measurements (referred to standard deviation values), which was higher in the Orbscan system $(0.03$ (0.02)) than in the ultrasound one $(0.10$ (0.05)), with significant statistical difference $(\mathrm{p}<0.0001$, df $66,95 \%$ CL $0.13 \mathrm{~mm}$ to 0.27 $\mathrm{mm})$.

\section{Discussion}

PACL has shown, during previous years, high security and predictability in the correction of high myopia. ${ }^{21-23}$ Nowadays the relevance of phakic intraocular implant (both in anterior or

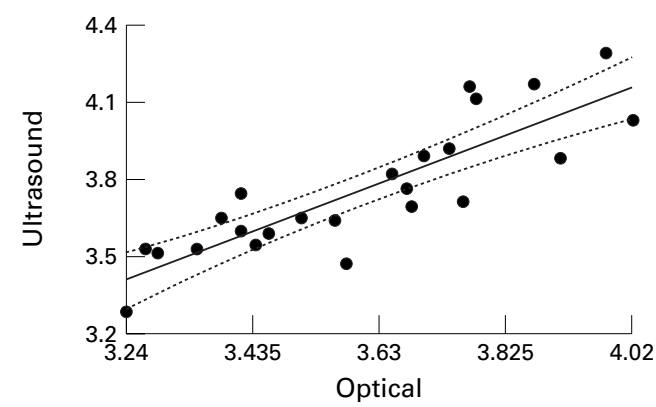

AC depth $(\mathrm{mm})$ in myopic eyes

Figure 2 Linear regression in the myopic sample.

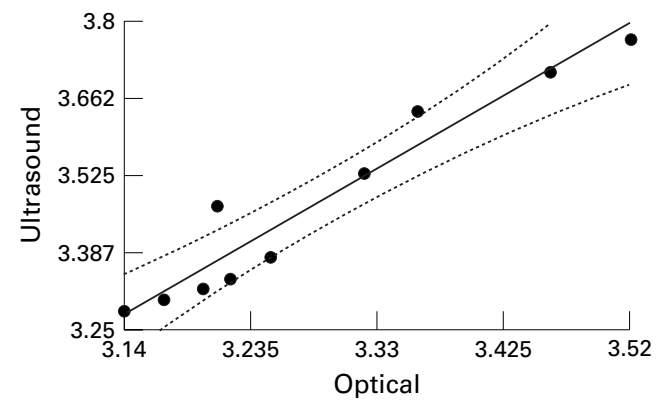

AC depth $(\mathrm{mm})$ in hyperopic eyes

Figure 3 Linear regression in the hyperopic sample. 


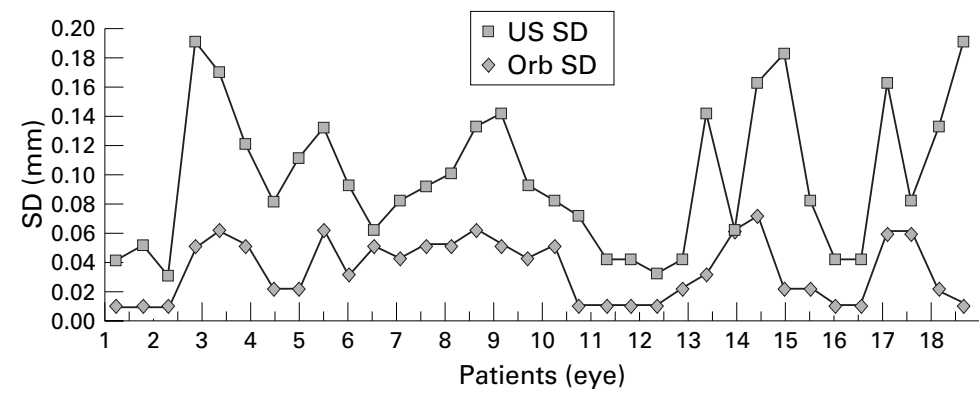

Figure 4 Standard deviation values in optical (Orbscan) and ultrasound (US) methods.

posterior chamber) is also growing for high hyperopia, because of the higher predictability shown if compared with photorefractive keratectomy. ${ }^{24-27}$

ACD measurement is an important factor in refractive surgery because of the different anatomical structure of myopic and hyperopic eyes. In high hyperopic eyes the anterior chamber is often shallower than the emmetropic one, even if racial differences were described..$^{28-30}$ In high myopic eyes, instead, there is not a direct relation among ACD and refraction, which is more related to axial length or to vitreous chamber elongation. ${ }^{31-33}$ However, in both high myopia and hyperopia PACL implant is hazardous when the ACD is shallower then $3 \mathrm{~mm}$. In fact, high power negative IOL may impact on the endothelium because of the proximity of its thick border to the cornea. ${ }^{13}$

Moreover, referring to the most used nomograms, an exact IOL power depends on the accuracy of ACD measurement. ${ }^{11} 12$

Anterior chamber echobiometry, both corneal and though the lid techniques, has become the gold standard in ACD measurement. The Orbscan topography system, initially developed as a corneal topography analyser, has recently introduced the possibility of measuring some characteristics of the anterior chamber, such as anterior chamber depth, volume, vertical, horizontal, radial, and axial angles. Auffarth and colleague ${ }^{20}$ showed good correlation between optical and ultrasonic measurements in a group of patients with cataract, using the prototype software version.

We used the latest version of the software (version 210M, Orbtek, Salt Lake City, UT, USA) in a group of patients affected by high myopia and high hyperopia.

Our experience confirms that ultrasound and optical ACD measurements are equivalent, even if the Orbscan underestimates ACD compared with ultrasound measurement of an average $0.17 \mathrm{~mm}$ (95\% CL $0.14 \mathrm{~mm}$ to 0.21 $\mathrm{mm})(\mathrm{SD} 0.10 \mathrm{~mm}), 4.68 \%(2.52 \%)(95 \% \mathrm{CL}$ $3.8 \%$ to $5.56 \%)$.

This results are similar to the values obtained by Auffarth in normal cataract affected eyes, even if the samples in this study were different with regard to the age and the refraction of the patients. Such a difference between the measurement systems also does not affect the safety of the implant: in fact, it does not significantly change the power of intraocular lens (for example, in Nuvita nomo- gram, IOL power varies by $0.1 \mathrm{D}$ for each 0.2 $\mathrm{mm}$ of ACD). Moreover, optical measurements are more repeatable than ultrasound ones, and preserve corneal integrity because it is a non-contact technique. Finally, ACD measurement by means of the Orbscan technique is an accurate method, repeatable, and easy to perform.

1 Olsen T, Corydon L, Gimbel H. Intraocular lens power calculation with an improved anterior chamber depth predicculation with an improved anterior chamber depth predic-

2 Fenzl RE, Gills JP, Cherchio M. Refractive and visual outcome of hyperopic cataract cases operated on before and after implementation of the Holladay II formula. Ophthalmology 1998;105:1759-64.

3 Thornval P, Naeser K. Refraction and anterior chamber depth before and after neodymium:YAG laser treatment for posterior capsule opacification in pseudophakic eyes: a prospective study. $\mathcal{F}$ Cataract Refract Surg 1995;21:457-60.

4 Arai M, Ohzuno I, Zako M. Anterior chamber depth after posterior chamber intraocular lens implantation. Acta Ophthalmol 1994; 72:694-7.

5 Ye T, Mao W, Lu D. Comparison of simple methods to screen predisposing eye of primary angle-closure glau-
coma. Chung Hua Yen Ko Tsa Chil 1995;31:341-4.

6 Congdon NG, Quigley HA, Hung PT, et al. Screening techCongdon NG, Quigley HA, Hung PT, et al. Screening tech-
niques for angle closure glaucoma in rural Taiwan. Acta niques for angle closure glaucoma
Ophthalmol Scand 1996;74:113-19.

7 Garner LF, Yap MK, Kinnear RF, et al. Ocular dimensions and refraction in Tibetan children. Optom Vis Sci 1995;72: 266-71.

8 Caronia RM, Liebmann JM, Stegman Z, et al. Increase in iris-lens contact after laser iridotomy for pupillary block angle closure. Am f Ophthalmol 1996;112:53-7.

9 Lowe RF. Aetiology of the anatomical basis for primary angle-closure glaucoma. Biometrical comparisons between normal eyes and eyes with primary angle-closure glaucoma. Br f Ophthalmol 1970;54:161-9.

10 Vinciguerra P, Azzolini M, Airaghi P, et al. Effect of decreasing surface and interface irregularities after photorefractive keratectomy and laser in situ keratomileusis on optical and functional results. F Refract Surg 1998;14:S199-203.

11 Van der Heijde G. Some optical aspects of implantation of an IOL in a myopic eye. Eur f Refract Surg 1989;1:245-8.

an IOL in a myopic eye. Eur $\mathcal{F}$ Refract Surg 1989;1:245-8.
2 Holladay J. Refractive power calculations for intraocular lenses in phakic eyes. Am f Ophthalmol 1993;116:63-6.

13 Baikoff G, Colin J. Damage to corneal endothelium using anterior chamber intraocular lenses for myopia. Refract Corneal Surg 1993;6:383.

14 Baikoff G, Arne JL, Bokobza Y, et al. Angle-fixated anterior chamber intraocular lens for myopia of -7 to -19 diopters. f Refract Surg 1998;14:282-93.

15 Pop M, Mansour M, Payette Y. Ultrasound biomicroscopy of the iris-claw phakic intraocular len for high myopia. $\mathcal{F}$ Refract Surg 1999;15:632-5.

16 Saragoussi JJ, Puech $M$, Assouline $M$, et al. Ultrasound biomicroscopy of Baikoff anterior chamber phakic intraocular lenses. I Refract Surg 1997;13:135-41.

17 Twelker JD, Kirschbaum S, Zadnik K, et al. Comparison of corneal versus through-the-lid A-scan ultrasound biomcorneal versus through-the-lid A-s

18 Yaylali V, Kaufman SC, Thompson HW. Corneal thickness measurements with the Orbscan Topography System and
ultrasonic pachymetry. F Cataract Refract Surg 1997;23: ultrasonic

19 Liu Z, Huang AJ, Pflugfelder SC. Evaluation of corneal thickness and topography in normal eyes using the Orbscan corneal topography system. Br F Ophthalmol 1999;83:7748.

20 Auffarth GU, Tetz MR, Biazid Y, et al. Measuring anterior chamber depth with the Orbscan Topography System. I Cataract Refract Surg 1997;23:1351-5.

21 Garrana RM, Azar DT. Phakic intraocular lenses for correction of high myopia. Int Ophthalmol Clin 1999;39:45-57.

22 Leroux-Les-Jardins S, Ullern M, Wethel AL. Myopic anterior chamber intraocular lens implantation: evaluation at 8 years. $\mathcal{F} \mathrm{Fr}$ Ophtalmol 1999;22:323-7.

23 Aliò JL, de-la-Hoz F, Perez Santonja JJ, et al. Phakic anterior chamber lenses for the correction of myopia: a 7-year chamber lenses for the correction of myopia: a 7-year
cumulative analysis of complications in 263 cases. Ophthalmology 1999;106:458-66.

24 Fechner PU, Singh D, Wulff K. Iris-claw lens in phakic eyes to correct hyperopia: preliminary study. $\mathcal{F}$ Cataract Refract Surg 1998;24:48-56.

25 Rosen E, Gore C. Staar Collamer posterior chamber phakic intraocular lens to correct myopia and hyperopia. $\mathcal{F}$ Cataract Refract Surg 1998;24:596-606.

26 Sanders DR, Martin RG, Brown DC, et al. Posterior chamber phakic intraocular lens for hyperopia. $\mathcal{F}$ Refract Surg 1999;15:309-315.

27 Davidorf JM, Zaldivar R, Oscherow S. Posterior chamber phakic intraocular lens for hyperopia of +4 to +11 diopters. 7 Refract Surg 1998;14:306-311.

28 Greene PR. Optical constants and dimensions for the myopic, hyperopic and normal rhesus eye. Exp Eye Res myopic, hyperopic

29 Pitts JF, Jay JL. The association of Fuchs's corneal endothelial dystrophy with axial hypermetropia, shallow anterior 
chamber, and angle closure glaucoma. $\mathrm{Br} \mathcal{F}$ Ophthalmol 1990;74:601-4.

30 Congdon NG, Youlin Q, Quigley $\mathrm{H}$, et al. Biometry and primary angle-closure glaucoma among Chinese, white, and black populations. Ophthalmology 1997;104:1489-95.

31 McBrien NA, Adams DW. A longitudinal investigation of adult-onset and adult-progression of myopia in an occupational group. Refractive and biometric findings. Invest $\mathrm{Oph}-$ thalmol Vis Sci 1997;38:321-33.
32 Goss DA, Van Veen HG, Rainey BB, et al. Ocular components measured by keratometry, phakometry, and ultrasonography in emmetropic and myopic optometry students. Optom Vis Sci 1997;74:489-95.

33 Lo PI, Ho PC, Lau JT, et al. Relationship between myopia and optical components - a study among Chinese Hong Kong student population. Yen Ko Hsueh Pao 1996;12:121- 